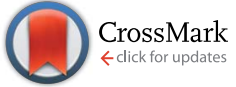

Cite this: RSC Adv., 2015, 5, 22869
Received 18th February 2015 Accepted 20th February 2015

DOI: $10.1039 / c 5 r a 03133 h$

\section{Oxygen reduction reaction at MWCNT-modified nanoscale iron(II) tetrasulfophthalocyanine: remarkable performance over platinum and tolerance toward methanol in alkaline medium $\uparrow$}

\begin{abstract}
Omobosede O. Fashedemi ${ }^{\mathrm{a}}$ and Kenneth I. Ozoemena*ab
A nanoscale iron(॥) tetrasulfophthalocyanine (nanoFeTSPc) catalyst obtained by co-ordinating with hexadecyltrimethylammonium bromide and subsequently anchored onto multi-walled carbon nanotubes (MWCNTs) for oxygen reduction reaction (ORR) has been reported. Two types of MWCNTs, hydroxyl/carboxyl-functionalized (o-MWCNTs) and sulfonate-functionalized (s-MWCNTs) were used as the supporting platforms for the catalysts (nanoFeTSPC-O-MWCNT and nanoFeTSPC-s-MWCNT, only 9 wt\% loading of the nanoFeTSPC). The nanoFeTSPC-O-MWCNT gave the best performance towards ORR in terms of high catalytic current density, more positive onset potential ( $E_{\text {onset }}=-0.02 \mathrm{~V} \mathrm{vs.} \mathrm{Ag} / \mathrm{AgCl}$ ), half-wave potential $\left(E_{1 / 2}=-0.32 \mathrm{~V} v \mathrm{~s}\right.$. $\left.\mathrm{Ag} / \mathrm{AgCl}\right)$, and high catalytic rate constant $\left(k \sim 1.6 \times 10^{-2} \mathrm{~cm} \mathrm{~s}^{-1}\right)$ compared to the nanoFeTSPC-s-MWCNT counterpart or the Pt/XC-72 (80\% Pt loading). The ORR performance generally follows this trend: nanoFeTSPC-O-MWCNT > Pt/XC-72 > nanoFeTSPC-S-MWCNT. The MWCNT-modified nanoFeTSPC complexes are much better than observed for the individual components, nanoFeTSPC, o-MWCNT and s-MWCNT. In addition, the nanoFeTSPC-o-MWCNT essentially followed a 4-electron pathway, while the nanoFeTSPC-s-MWCNT followed a 2-electron pathway. The excellent performance of the nanoFeTSPC-O-MWCNT correlates very well with the more homogenous dispersion and higher degree of attachment of the nanoFeTSPC on the surface of the o-MWCNT than on the s-MWCNTs. Unlike Pt/XC-72, the nanoFeTSPC-O-MWCNT exhibited excellent tolerance toward methanol contamination. The excellent ORR activity of the nanoFeTSPC-O-MWCNT at a very low catalyst loading, coupled with its excellent methanol tolerance compared to the commercial platinum, promises to serve as a viable non-noble alternative to the expensive noble metal catalysts (such as Pt and Pd) for alkaline fuel cells.
\end{abstract}

\section{Introduction}

In fuel cell technology, especially alkaline fuel cells (AFCs), oxygen reduction reaction (ORR) with non-noble metal-based catalysts has remained a field of intense research activities., ${ }^{1,2}$ ORR, which is a cathodic process, provides maximum energy only when the oxygen molecule is completely reduced to water via the 4-electron rather than the 2-electron pathway. ${ }^{3,4}$ Platinum, the most effective electrocatalyst for the ORR, is scarce and extremely expensive thus limiting the widespread largescale development of AFC for day-to-day application for electricity generation. Thus, there has been a desperate search in the fuel cell community for low-cost and efficient non-noble

${ }^{a}$ Department of Chemistry, University of Pretoria, Pretoria 0002, South Africa

${ }^{b}$ Energy Materials, Materials Science and Manufacturing, Council for Scientific \& Industrial Research (CSIR), Pretoria 0001, South Africa. E-mail: kozoemena@csir.co. za; Fax: +27 128412135; Tel: +27128413664

$\dagger$ Electronic supplementary information (ESI) available. See DOI: $10.1039 / \mathrm{c} 5 \mathrm{ra} 03133 \mathrm{~h}$ metal catalysts to replace Pt catalyst. $\mathrm{M}-\mathrm{N}_{4}$ macrocycles, notably the iron phthalocyanine (FePc) complexes, have been demonstrated as efficient catalyst for ORR, first by Jasinski ${ }^{5}$ and then by other workers. ${ }^{6-8}$ Despite efforts for developing FePcbased catalysts for ORR, there has been no significant progress to develop FePc-based catalyst that can out-perform Pt in ORR activities. Few reports that have shown some promise to compete with Pt have done so at extremely high catalyst loadings (between 20 and 75\%). For example, Dong et al. ${ }^{6}$ studied FePc (20 wt $\%$ ) on SWCNT for ORR, Mamuru et al. ${ }^{7}$ investigated Pt-based FePc complex (50 wt\%) on MWCNT, Jiang et al. ${ }^{9}$ showed that $50 \mathrm{wt} \%$ of FePc supported on graphene could give the best performance for ORR compared to Pt, while Cui et al. ${ }^{10}$ reported the best ORR in alkaline with $75 \mathrm{wt} \%$ of $\mathrm{FePc}(\mathrm{CP})_{4}$ on graphene. Some of the obvious reasons for such high catalyst loading can easily be attributed to the poor dispersibility and anchorage of the FePc-based catalyst on the carbon supporting platforms. To solve this problem, there is need to design and prepare an easily dispersible FePc-based complex that will 
strongly anchor on the conductive carbon supports. In addition, there is need for such FePc-based catalyst to be nanostructured with a view to increasing its surface area for enhanced ORR activity.

Iron(II) tetrasulfophthalocyanine (FeTSPc) is a member of the FePc family. However, unlike other members of this family, FeTSPc is well recognised for its high solubility on aqueous solutions, and has found applications in several areas of catalysis $^{11,12}$ to sensing ${ }^{13,14}$ and photo catalysis. ${ }^{15-17}$ The high solubility of FeTSPc has limited its application in heterogeneous catalysis such as the ORR. In this work, we have produced an organo-soluble nanostructured FeTSPc incorporating longchain alkane of the CTAB via coordinate covalency with a slight modification of a similar procedure by Sanchez et al. ${ }^{18}$ To explore the impact of surface functional groups on MWCNT support, this organo-soluble nanostructured FeTSPc (nanoFeTSPc) was subsequently integrated on sulfonate-functionalised $(s$-MWCNT) and carboxyl/hydroxyl-functionalised MWCNTs (oMWCNT). The choice for MWCNTs as a support is based on its high conductivity, and functionalising them with carboxylic $(\mathrm{COOH})^{19,20}$ and sulfonic groups $\left(\mathrm{SO}_{3} \mathrm{H}\right)^{21-23}$ will enhance their dispersibility in aqueous media.

In this study, the nanoFeTSPc loading on MWCNT was $9 \%$ of the total weight. To our knowledge, this is the lowest loading of any MPc catalyst on carbon support ever reported in the literature for ORR. We clearly demonstrate that the as-prepared nanoFeTSPc- $o$-MWCNT exhibits a 4-electron ORR pathway and extraordinary tolerance to possible methanol cross-over compared with the commercial Pt/XC-72 (80\% Pt wt) for ORR in alkaline medium.

\section{Experimental}

\section{Materials and reagent}

Iron(II) tetrasulfophthalocyanine (FeTSPc) was synthesized following an established procedure described elsewhere. ${ }^{24}$ Hexadecyltrimethylammonium bromide $\left(\mathrm{C}_{16} \mathrm{H}_{33} \mathrm{~N}^{+}\left(\mathrm{CH}_{3}\right)_{3} \mathrm{Br}^{-}\right.$, CTAB) was obtained from Merck. Multi-walled carbon nanotubes (MWCNTs, Shenzhen Nanotech Port Co., Ltd., China, 20$40 \mathrm{~nm}$ in diameter and 1-2 $\mu \mathrm{m}$ in length) were first acid-treated to obtain the oxo-functionalised MWCNTs (o-MWCNTs) ${ }^{20}$ and subsequently functionalized with sulfonic acid group using the established procedure $^{25}$ (abbreviated herein as $s$-MWCNTs). Commercial Pt/XC-72 (C1 - 80, 80\% HP Pt on Vulcan XC-72, Lot \#D0490315) was obtained from the BASF Fuel Cell, Inc., Somerset, NJ, USA. N,N-Dimethylformamide (DMF, SigmaAldrich) was distilled and dried before use. Ultra-pure water of resistivity 18.2 $\mathrm{M} \Omega \mathrm{cm}$ was obtained from a Milli-Q Water System (Millipore Corp. Bedford, MA, USA) and was used throughout for the preparation of solutions.

\section{Synthesis of nanoFeTSPc, nanoFeTSPc-o-MWCNT and nanoFeTSPc-s-MWCNT}

The formation of nanoFeTSPc and subsequent integration with MWCNTs follows similar procedure reported elsewhere, ${ }^{\mathbf{2 6}}$ and it is schematically represented here for clarity (Scheme 1). Briefly stated, a mixture of FeTSPc and CTAB (mole ratio of $1: 4$ ) was dissolved in deionized water and $1 \mathrm{mM} \mathrm{NaOH}$, ultrasonicated, and then stirred with a magnetic stirrer at ca. $50{ }^{\circ} \mathrm{C}$ for $2 \mathrm{~h}$. The resulting crude product was washed several times with $20 \mathrm{~mL}$ warm water ( $\mathrm{ca} .40{ }^{\circ} \mathrm{C}$ ) and finally with pentane. The darkcoloured product was oven-dried at $70{ }^{\circ} \mathrm{C}$. A mixture of nanoFeTSPc (3 mg) and $o$-MWCNTs $(30 \mathrm{mg}$ ) was added into $40 \mathrm{~mL}$ ethylene glycol in a $250 \mathrm{~mL}$ Erlenmeyer flask, ultrasonically dispersed for $30 \mathrm{~min}$, and then subjected to microwave irradiation (with a liner-rotor 16 F100 TFM vessel, Multiwave 3000 sample preparation system, 1400 Watts, Anton Paar) and heated at $1 \mathrm{~kW}, 190^{\circ} \mathrm{C}$ for $60 \mathrm{~s}$. The resulting suspension was separated by filtration and the obtained residue washed with acetone and deionised water. The final product (nanoFeTSPc- $o$-MWCNT) was dried at $110{ }^{\circ} \mathrm{C}$ overnight in an oven. The same procedure was used for the preparation of nanoFeTSPc-s-MWCNT but using the $s$-MWCNTs.

\section{Equipment and procedure}

XRD data were obtained from a PANalytical X'Pert Pro powder diffractometer X'Celerator and a variable divergence and receiving slits with Fe filtered Co $\mathrm{K} \alpha$ radiation. The phases were identified using X'Pert Highscore plus software. Transmission

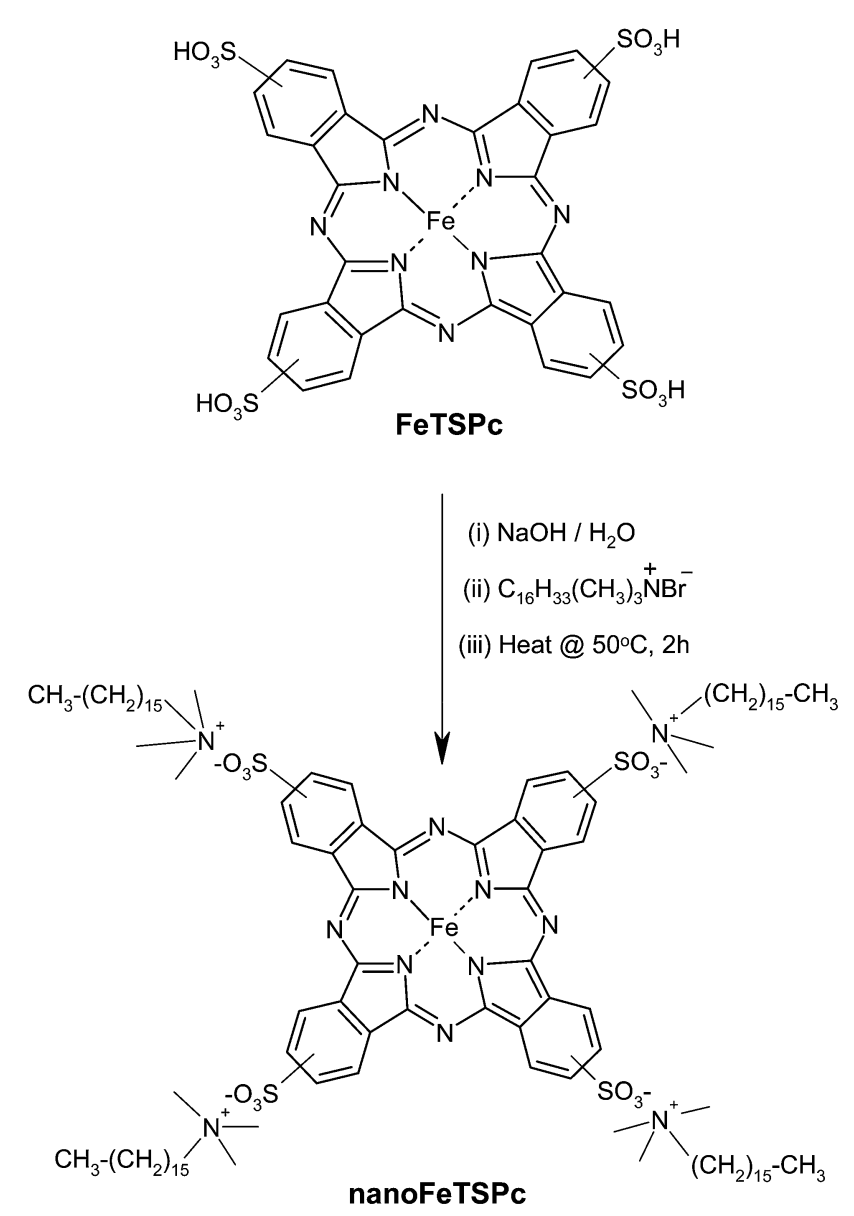

Scheme 1 Schematic representation of the synthesis of nanoFeTSPC from pristine FeTSPC. 
electron microscopy Fourier transmission infrared spectroscopy (FTIR) analyses were carried out using a Bomem (Hartmann \& Braun), model MB-102 spectrophotometer. The UVvisible spectra were recorded using a Cary 300 UV-visible Spectrophotometer, driven by Varian software version 3.0. Transmission electron microscopy (TEM) images were taken on a JEOL JEM 2000EX microscope at an accelerating voltage of $200 \mathrm{kV}$. Specimens for all of the TEM analyses were prepared by dispersing the nanoparticles in methanol, sonicating for $1 \mathrm{~min}$ to ensure adequate dispersion of the nanostructures, and evaporating one drop of the solution onto 300 mesh $\mathrm{Cu}$ grid, coated with a lace carbon film. Scanning electron microscopy (SEM) images were obtained utilizing a field emission scanning electron microscope (FESEM Zeiss-Leo DSM982).

\section{Electrochemical measurements}

All electrochemical experiments were carried out using an Autolab Potentiostat PGSTAT 100 (Eco-Chemie, Utrecht, The Netherlands) driven by version 4.9 of GPES and FRA software. A glassy carbon electrode (GCE, dia $=3 \mathrm{~mm}$, Autolab) was used as the working electrode for cyclic and linear voltammetry (CV and LSV) testing, while a rotating disk electrode (RDE, GCE, diameter $=5 \mathrm{~mm}$, Autolab) was used as the working electrode for the rotating disk experiments. In all cases, a Pt rod and $\mathrm{Ag} / \mathrm{AgCl}$ (saturated $3 \mathrm{M} \mathrm{KCl}$ ) were used as a counter and reference electrode, respectively. The catalyst ink was prepared by simply dispersing $1 \mathrm{mg}$ of the nanoFeTSPc/MWCNT in $1 \mathrm{~mL}$ of ethanol containing $100 \mu \mathrm{L}$ of $5 \%$ Nafion. The mixture was ultrasonicated for $3 \mathrm{~min}$ to make a uniform ink. The working electrode was prepared by drop-casting $c a .6 \mu \mathrm{L}$ of the catalyst ink onto the active area of the GCE and drying in an oven at $60{ }^{\circ} \mathrm{C}$ (meaning that the loaded mass of nanoFeTSPc on the electrode was approximately $5.45 \times 10^{-4} \mathrm{mg}$ ). The same procedure was used to prepare the $\mathrm{Pt} / \mathrm{XC}-72$, giving an estimated loaded $\mathrm{Pt}$ catalyst on the electrode as $4.8 \times 10^{-3} \mathrm{mg}$. The electrochemistry experiments were performed in high purity $\mathrm{N}_{2}\left(\right.$ or $\left.\mathrm{O}_{2}\right)$ saturated $0.1 \mathrm{M} \mathrm{KOH}$. For the ORR activity test, linear scans were conducted using the same voltage from 300-4000 rpm in $0.1 \mathrm{M}$ $\mathrm{KOH}$ bubbled with high purity $\mathrm{O}_{2}$. All the electrochemical experiments were conducted at room temperature $\left(25 \pm 1^{\circ} \mathrm{C}\right)$. Each experiment was performed at least five times.

\section{Results and discussion}

\section{Spectroscopic and microscopic characterisation}

Fig. 1 compares the IR spectra of the pristine FeTSPc and its nanoFeTSPc counterpart. Both FeTSPc and nanoFeTSPc displayed the main absorption bands for iron(II) phthalocyanine (FePc) at $c a .1000 \mathrm{~cm}^{-1}$, this is normally seen at about $994 \mathrm{~cm}^{-1}$. The strong absorption peak at $1107 \mathrm{~cm}^{-1}$ is characteristic of the symmetric and anti-symmetric stretching motions assigned to the $\mathrm{O}=\mathrm{S}=\mathrm{O}$ group coupled with the absorption band at $1190 \mathrm{~cm}^{-1}$. The peaks observed at 701,843 and $1171 \mathrm{~cm}^{-1}$ are attributed to the out-of-plane $\mathrm{C}-\mathrm{H}$ deformations of the aromatic groups. ${ }^{28}$ The typical stretching bands of aromatic $\mathrm{C}=\mathrm{C}$ groups can be seen at $1637 \mathrm{~cm}^{-1} \cdot{ }^{18,27,28}$ The nanoFeTSPc displayed

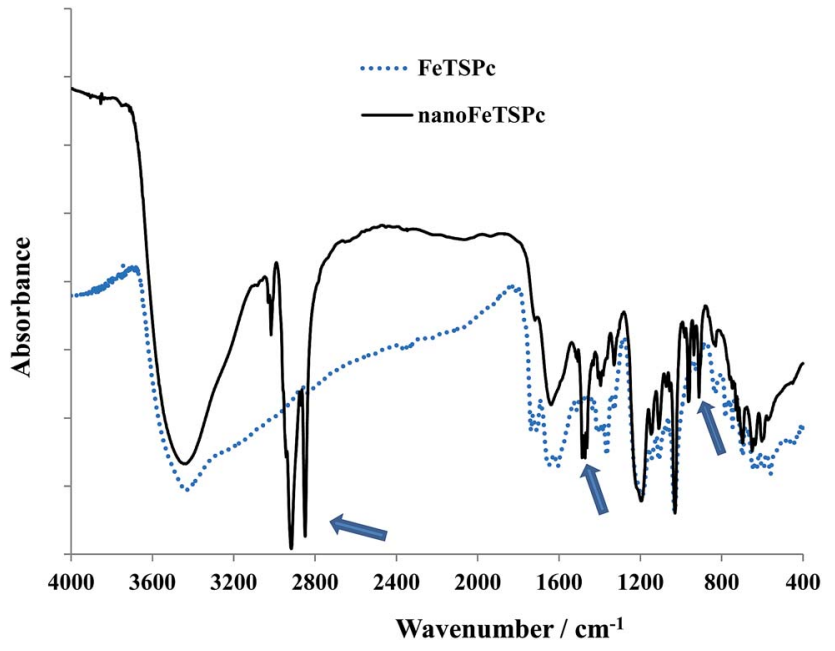

Fig. 1 Comparative IR spectra of nanoFeTSPc and FeTSPC. The arrows show the additional peaks of the nanoFeTSPc relating to the long alkane chain of the CTAB.

additional bands (encircled in broken lines) with the intense peak of the $\mathrm{C}-\mathrm{H}$ group of alkylammonium chains around $2919 \mathrm{~cm}^{-1},^{18}$ intense peaks around $3100 \mathrm{~cm}^{-1}$ and $995 \mathrm{~cm}^{-1}$ due to olefinic groups, and peaks of methyl and methylene groups around $2980-2850 \mathrm{~cm}^{-1}$ and $1480 \mathrm{~cm}^{-1} \cdot{ }^{28}$ These results confirm the modification of the structure of the pristine FeTSPc with the hydrophobic long-chain alkane of the CTAB molecule.

The effect of the long-chain alkane on the hydrophobicity of the nanoFeTSPc was evident from the UV-vis measurement performed in DMF (Fig. 2). The FeTSPc and nanoFeTSPc showed the characteristic absorption B and Q bands at $c a .350$ and $685 \mathrm{~nm}$, respectively. Also, both complexes showed weak band peak around $430 \mathrm{~nm}$, which confirmed the low-spin sixcoordinate $\mathrm{Fe}(\mathrm{II}) \mathrm{Pc}$ species due to the metal-to-ligand charge transfers (MLCT) for FeTSPc and nanoFeTSPc respectively. ${ }^{\mathbf{2 9 , 3 0}}$ However, unlike the FeTSPc, the nanoFeTSPc gave a broad shoulder peak in the $710-750 \mathrm{~nm}$ region. Shoulder peak in the

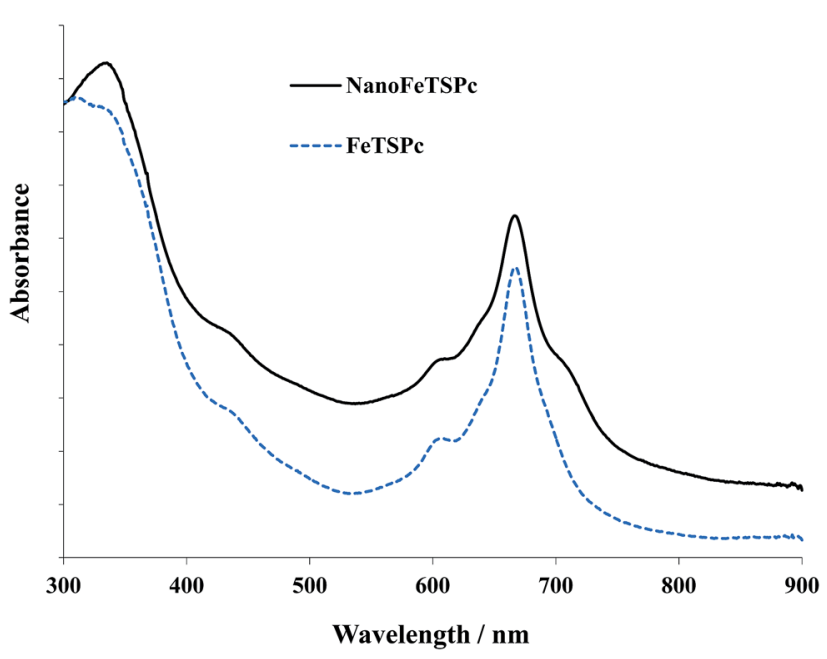

Fig. 2 Typical UV-vis spectra of FeTSPc and nanoFeTSPc in DMF. 
high energy side of the Q band is usually due to poor solubility and molecular aggregation ${ }^{\mathbf{1 5 , 3 1 , 3 2}}$ and, in this case, most probably must have arisen from the long chain alkane substituents from the CTAB. The successful grafting of the long alkyl chain onto the FeTSPc molecule caused steric hindrance, hence poor dispersion in solvent compared to the pristine FeTSPc molecule.

Fig. 3 compares the FESEM images of the MWCNTsmodified nanoFeTSPc complexes, nanoFeTSPc- $o$-MWCNT (Fig. 3A) and nanoFeTSPc-s-MWCNT (Fig. 3C), and their corresponding TEM images (nanoFeTSPc- $o$-MWCNT (Fig. 3B) and nanoFeTSPc-s-MWCNT (Fig. 3D)).

The TEM images show that the nanoFeTsPc composites are evenly distributed onto the $o$-MWCNTs compared to the $s$-MWCNTs, a property that should favour the electrocatalytic properties of the nanoFeTSPc- $o$-MWCNT over the nanoFeTSPc$s$-MWCNT counterpart. Also, the FESEM and TEM images confirm that the pristine FeTSPc is bulky, micron-sized compared the nano-sized nanoFeTSPc (see ESI, Fig. S1 $\dagger$ ). The EDX spot analysis (see ESI, Fig. S2 $\dagger$ ) provided semi-quantitative information on elemental concentrations of the FeTSPc and nanoFeTSPc at different locations in the film. A typical atomic percent gave $\mathrm{S}=$ $24.95 \pm 0.23 \%$ and $\mathrm{Fe}=5.85 \pm 0.22 \%$, which is the expected atomic ratio of $\mathrm{Fe}: 4 \mathrm{~S}$ for the FeTSPc. The result also suggests less than $7 \%$ of impurities of surface bromine generated from the unreacted ammonium head groups of the CTAB upon coordinate covalency bonding with the FeTSPc (see Scheme 1).

\section{Oxygen reduction reaction}

Fig. 4 compares the cyclic voltammetric evolutions of the nanoFeTSPc- $o$-MWCNT, nanoFeTSPc-s-MWCNT and Pt/XC-72 in oxygen-saturated $0.1 \mathrm{M} \mathrm{KOH}$ solution. Fig. 5 compares the linear sweep RDE plots with current densities calculated as a function of the geometric area of the electrode (Fig. 5A) and active mass of the electrocatalyst (Fig. 5B). The second reduction wave potential for both catalysts starts at about $-0.2 \mathrm{~V}$. This has been observed with FePc on MWCNT. ${ }^{33}$ Although two-wave RDE curve is typical for FePc-based catalysts catalyst for ORR, ${ }^{9}$ it is rarely seen with Pt. Nevertheless, two-wave curve for ORR in Pt catalysts have been reported by other workers using Pt as ORR catalysts in alkaline media, and related to surface structures. For example, Rizo et al. ${ }^{34}$ studied ORR on stepped Pt surfaces in alkaline media, the Pt (111) surface exhibited a consistent "double waves" in all its ORR spectra. Also, Yue et al. ${ }^{35}$ observed the same phenomenon in a study on the generation of $\mathrm{OH}$ radicals by $\mathrm{Pt}$ alloy catalysts in alkaline media.
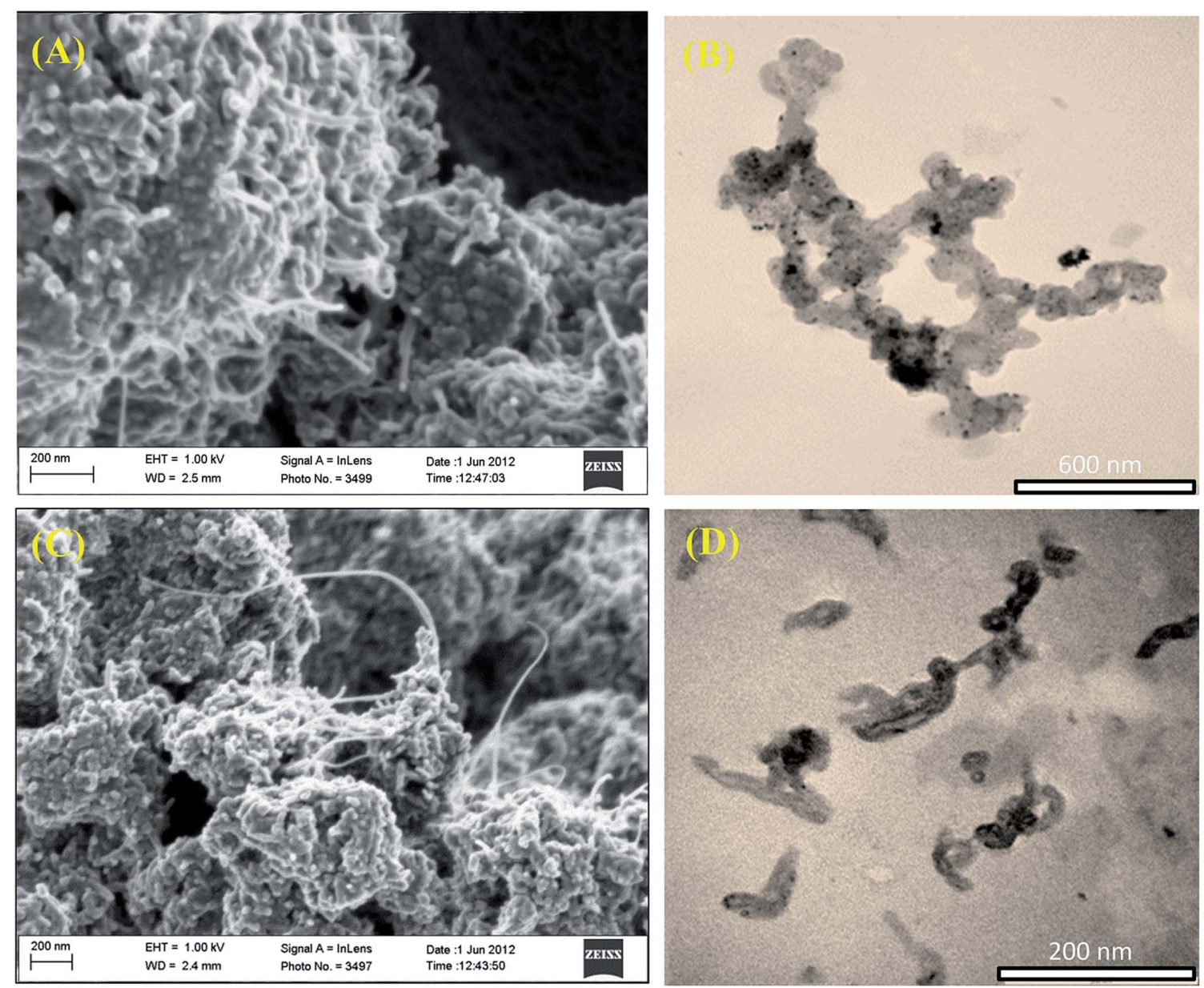

Fig. 3 FESEM images of the nanoFeTSPC-O-MWCNT (A) and nanoFeTSPC-S-MWCNT (C), and their corresponding TEM images (B) and (D), respectively. 


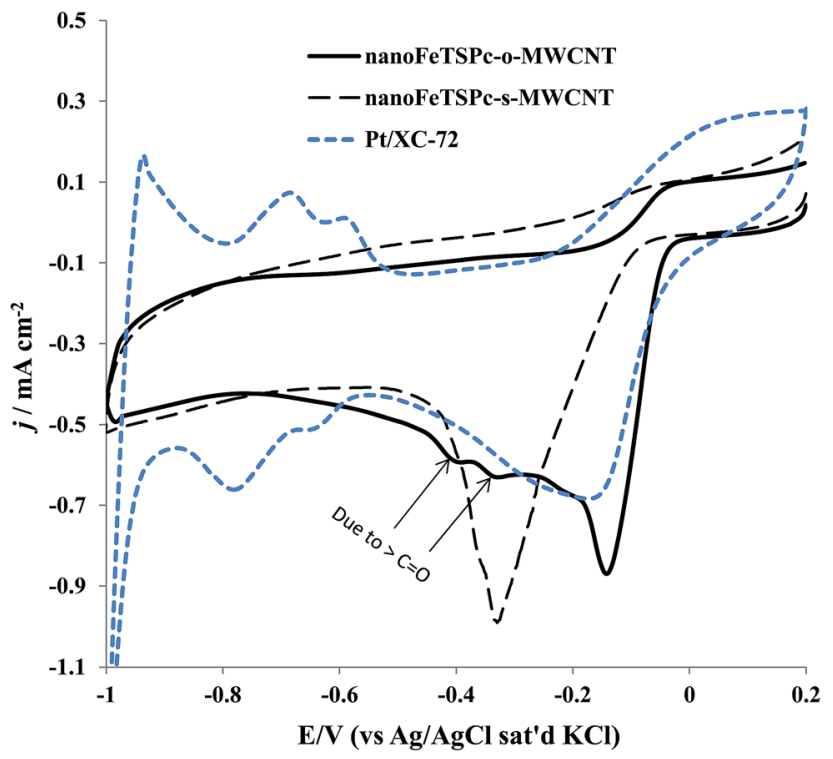

Fig. 4 Cyclic voltammograms at $25 \mathrm{mV} \mathrm{s}^{-1}$ of the nanoFeTSPC-OMWCNT, nanoFeTSPC-s-MWCNT and Pt/XC-72 in oxygen-saturated $0.1 \mathrm{M} \mathrm{KOH}$ solution.

From the RDE plots (Fig. 5A), the onset ORR potential for the nanoFeTSPc- $o$-MWCNT and Pt/XC-72 is at $c a$. $-0.02 \mathrm{~V}$ while that of nanoFeTSPc-s-MWCNT is higher $(c a .-0.20 \mathrm{~V})$. The limiting current density for the nanoFeTSPc-o-MWCNT is higher than the other two catalysts (nanoFeTSPc- $o$-MWCNT and Pt/XC-72) under the same rotation speed. In addition to geometric area current density $\left(\mathrm{mA} \mathrm{cm} \mathrm{cm}^{-2}\right.$ ) we also measured the active mass current density $\left(\mathrm{mA} \mathrm{mg}^{-1}\right)$. The cost of the catalyst and the amount of it required for efficient power generation determine the viability of a new catalyst material for application in fuel cell application, thus the active mass current density is necessary to understand the best-performing electrocatalysts. From this work, as evident in Fig. 5B, the nanoFeTSPc catalyst ( $9 \mathrm{wt} \%$ on MWCNT) showed much higher mass current density than the Pt ( $80 \mathrm{wt} \%$ on Vulcan carbon black). Pt is a poor performer as an ORR catalyst in alkaline electrolytes, which explains why non-Pt catalysts are generally preferred for ORR in alkaline media. Also, our result is consistent with the recent report of Jiang et al. ${ }^{9}$ where unsubstituted iron(II) phthalocyanine supported on graphene (50 wt\% FePc on graphene) gave better ORR performance over Pt/C (20 wt\% Pt on Vulcan carbon black).

From RDE data, it is also observed that the diffusion-limited current densities for the different materials are slightly different, although they should always be the same. This behaviour has been observed by others for MWCNT-based electrodes, ${ }^{36-38}$ and was related to the morphology of the electrode materials which leads to a change in the diffusion regime (i.e., semi-infinite linear diffusion and/or thin layer diffusion processes). ${ }^{36,39}$ We attribute this behaviour to mainly the thin layer diffusion process; oxidation of electroactive species/electrolytes trapped in pockets in between the high surface area porous nanotubes.

In general, the ORR data of the $\mathrm{CV}$ and $\mathrm{RDE}$ are comparable and, as summarised in Table 1 using the RDE data, the nanoFeTSPc-o-MWCNT catalyst gave the best electrocatalytic
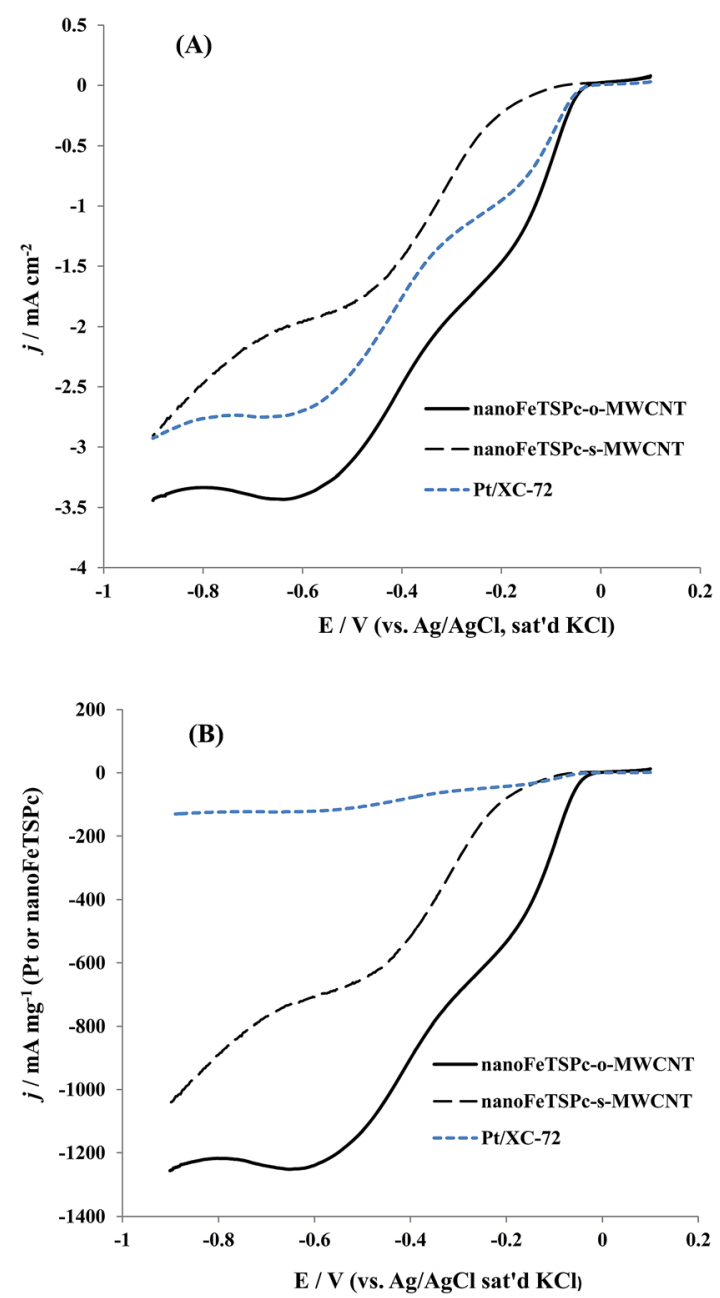

Fig. 5 RDE curves (at $1500 \mathrm{rpm}$, LSV at $10 \mathrm{mV} \mathrm{s}^{-1}$ ) for the nanoFeTSPC-O-MWCNT, nanoFeTSPC-s-MWCNT and Pt/XC-72 in oxygensaturated $0.1 \mathrm{M} \mathrm{KOH}$ solution with current densities calculated as a function of the (A) geometric area of the electrode, and (B) active mass of the electrocatalyst.

performance in terms of current density $\left(j_{\text {orr }}\right)$, onset potential ( $\left.E_{\text {onset }}\right)$, and half-wave potential $\left(E_{1 / 2}\right)$ decreasing as follows: nanoFeTSPc- $o$-MWCNT > Pt/XC-72 > nanoFeTSPc-s-MWCNT. The ORR data of the individual components, nanoFeTSPc, $o$ MWCNT and $s$-MWCNT are very poor compared to the nanocomposites or Pt/XC-72 (see ESI, Fig. S3†). In addition to its welldefined ORR peak, it is evident that the CV of the nanoFeTSPc- $o$ MWCNT for the ORR showed a pair of weak but broad peaks due to the quinolic and/or carbonyl groups $(>\mathrm{C}=\mathrm{O})$ of the acidfunctionalised MWCNTs ${ }^{\mathbf{4 0 - 4 2}}$ (see the two peaks shown with arrows in Fig. 4).

To gain an insight into the ORR, RDE experiments were performed at different rotation speeds in oxygen-saturated 0.1 $\mathrm{M} \mathrm{KOH}$ solution for the three different electrocatalysts, nanoFeTSPc-o-MWCNT (Fig. 6A), nanoFeTSPc-s-MWCNT (Fig. 6C) and Pt/XC-72 (Fig. 6E). The polarization curves display a steady increase in limiting current as the rotation speed increases and there is a clear pre-wave present at low overpotentials for nanoFeTSPc-o-MWCNT and Pt/XC-72. Also, while the 
Table 1 Summary of the ORR activities of the electrocatalysts studied using RDE (1500 rpm, at a linear sweep rate of $10 \mathrm{mV} \mathrm{s}{ }^{-1}$ in oxygensaturated $0.1 \mathrm{M} \mathrm{KOH}$ solution). All potential recorded versus $\mathrm{Ag} / \mathrm{AgCl}$, saturated $\mathrm{KCl}$. Each experiment was performed five times with the mean and standard deviation reported in the table

\begin{tabular}{|c|c|c|c|c|}
\hline Catalysts & $E_{\text {onset }} / \mathrm{V}$ & $E_{1 / 2} / \mathrm{V}$ & $J_{\text {orr }} / \mathrm{mA} \mathrm{cm}^{-2}$ & $J_{\text {orr }} / \mathrm{mA} \mathrm{mg}^{-1}$ \\
\hline nanoFeTSPc-o-MWCNT & $-0.020 \pm 0.001$ & $-0.32 \pm 0.01$ & $3.43 \pm 0.17$ & $1248 \pm 63$ \\
\hline nanoFeTSPc-s-MWCNT & $-0.200 \pm 0.007$ & $-0.40 \pm 0.01$ & $2.91 \pm 0.15$ & $1028 \pm 52$ \\
\hline $\mathrm{Pt} / \mathrm{XC}-72$ & $-0.020 \pm 0.001$ & $-0.37 \pm 0.02$ & $2.91 \pm 0.15$ & $131 \pm 37$ \\
\hline
\end{tabular}

polarization curves for nanoFeTSPc-o-MWCNT gave very steady plateaux in the high potential range for all the rotation speeds studied, nanoFeTSPc-s-MWCNT and Pt/XC-72 did not display such features; instead one observes a more inclined plateau as rotation speed increases. At every rotation speed, the ORR data ( $E_{\text {onset }}, E_{1 / 2}$ and $E_{\text {orr }}$ ) still follows the values reported in Table 1; nanoFeTSPc- $o$-MWCNT (Fig. 6A) and Pt/XC-72 (Fig. 6E) started at $c a$. $-0.02 \mathrm{~V}$ while that of nanoFeTSPc-s-MWCNT (Fig. 6C) began at $c a$. $-0.20 \mathrm{~V}$. The limiting current densities for nanoFeTSPc-o-MWCNT are higher than the other two under the same rotation rates (100-4000 rpm). The number of electrons involved in the ORR was obtained from the conventional Koutecky-Levich (K-L) equation (eqn (1)): ${ }^{\mathbf{4 3}}$

$$
\frac{1}{j}=\frac{1}{j_{\mathrm{d}}}+\frac{1}{j_{\mathrm{k}}}=\frac{1}{0.21 n F C_{\mathrm{O}_{2}} D^{2 / 3} \gamma^{1 / 6} \omega^{1 / 2}}+\frac{1}{n F k C_{\mathrm{O}_{2}}}
$$

where $j$ is the measured current, $j_{\mathrm{d}}$ is the diffusion-limiting current, $j_{\mathrm{k}}$ is the kinetic current, $n$ is the number of electrons transferred, $F$ is the Faraday constant, $D$ is the diffusion coefficient $\left(1.95 \times 10^{-5} \mathrm{~cm}^{2} \mathrm{~s}^{-1}\right), \gamma$ is the kinematic viscosity (8.98 $\left.\times 10^{-3} \mathrm{~cm}^{2} \mathrm{~s}^{-1}\right), C_{\mathrm{O}_{2}}$ is the oxygen concentration $\left(1.15 \times 10^{-3}\right.$ mol $\left.\mathrm{dm}^{-3}\right), \omega$ is the rotation speed, and $k$ is the kinetic rate constant. The linearity of the K-L plots $j^{-1}$ vs. $\omega^{-1 / 2}$, Fig. 6B, D and $\mathrm{F}$ ) is indicative that the reaction is first order, and controlled by kinetics at the electrode surface as well as mass transport of oxygen species. As exemplified in Fig. 6B, D and F, the voltages used for our calculations were picked from within the mixed kinetic-diffusion region which encompasses the "two-wave" region $(-0.32$ to $-0.6 \mathrm{~V})$. Typical values obtained at $-0.32 \mathrm{~V}$ (for five trials) are summarised in Table 1 . From the $\mathrm{K}-\mathrm{L}$ plot of the nanoFeTSPc-o-MWCNT (Fig. 6B) the number of transferred electrons ( $n$ ) was calculated as $3.7 \pm 0.2$ (ca. 4), which is in good agreement with values obtained by others for the FePc and FeTSPc which are known to undergo ORR with production of water through the 4-electron reduction pathway in alkaline media., ${ }^{\mathbf{1 , 4}}$

For the Pt/XC-72 (Fig. 6F), the $n$ value $3.9 \pm 0.1$ (ca. 4) in agreement with several reports. ${ }^{45-47}$ However, for the nanoFeTSPc-s-MWCNT (Fig. 6D) the $n$ value was obtained as $2.1 \pm$ 0.1 , indicating a 2-electron pathway reduction for oxygen. This result is unexpected and could be due to the effect of the sulfonate-functionalised MWCNTs. Some Fe-based $\mathrm{N}_{4}$-macrocylic catalysts have been known to undergo ORR pathways different from the usual 4-electron path due to the effect of substituents or ligands attached to the macrocycle. ${ }^{48-50}$ For example, Baker et al. $^{49}$ also observed a 2-electron pathway for the FeTSPc. Detailed studies are required to understand the higher performance of the $o$-MWCNT over the $s$-MWCNTs. However, according to several authors, ${ }^{48-50}$ the FeTSPc complex forms adducts with oxygen (nucleophilic $\left[\mathrm{SO}_{3} \mathrm{H}\right]^{-}$groups form adducts with carbonyls $[\mathrm{C}=\mathrm{O}]$ of aldehydes, methyl ketones and cyclohexanones) thus the large onset potential for the ORR could be the result of the reduction of the adduct with the peripheral sulfonate group before the FePc catalyst can participate in the ORR. This interpretation may also be the reasoning behind the activity of our nanoFeTSPc-s-MWCNT. Considering that the nanoFeTSPc and $s$-MWCNTs contain sulfonate group, there is an excessive amount of surface $\left(-\mathrm{SO}_{3} \mathrm{H}\right)$ groups bound to the catalysts which can readily lead to the formation of adducts with oxygen or hydroxide anions or other free carbonyls on the functionalised carbon nanotubes.

The kinetic rate constants $(k)$, obtained from the $\mathrm{K}-\mathrm{L}$ analysis using the same potentials for all the catalysts, were estimated as $1.57 \times 10^{-2}, 1.38 \times 10^{-2}$ and $1.48 \times 10^{-2} \mathrm{~cm} \mathrm{~s}^{-1}$ for the nanoFeTSPc- $o$-MWCNT, nanoFeTSPc-s-MWCNT and Pt/XC72 , respectively. When considered the low percentage loading of the nanoFeTSPc, these values are better and comparable to those reported for other substituted FePc including some with incorporation of noble metals like Pt. ${ }^{7,44}$ The Tafel slope $(b)$ is obtained by correcting the polarization curve for mass diffusion for the first order reaction, wherein: ${ }^{51}$

$$
\begin{gathered}
j_{\mathrm{k}}=\frac{j}{j_{\mathrm{d}}-j} \\
E_{\mathrm{app}}=E_{\mathrm{eq}}-b \log j_{\mathrm{k}} \\
E_{\text {app }}=E_{\text {eq }}-\frac{R T}{\alpha n F} \log j_{\mathrm{k}}
\end{gathered}
$$

where $E_{\text {app }}$ is the applied potential, $E_{\text {eq }}$ is the equilibrium potential, $j_{\mathrm{k}}$ is the kinetic current density, $j_{\mathrm{d}}$ is the diffusionlimiting current density at a given potential. The plot of $E_{\text {app }}$ vs. $\log j_{\mathrm{k}}$ yielded Tafel slope values for nanoFeTSPc-o-MWCNT, nanoFeTSPc-s-MWCNT and Pt/XC-72 were obtained as 216, 371 and $53 \mathrm{mV} \mathrm{dec}{ }^{-1}$, respectively. The high Tafel values for the MWCNT-based catalysts are related to the porosity of the modified electrodes. Table 2 compares the ORR kinetic parameters obtained from this work with those reported recently in the literature. It is interesting to note that this is the lowest loading of any MPc catalyst on carbon support ever reported in the literature exhibiting an extra-ordinary performance for ORR over commercial platinum catalyst in alkaline media. The high-performance of the nanoTeTSPc over the other FePc complexes in the literature (Table 2) may be related to the CTAB. The negatively charged FeTSPc are adsorbed on positively 

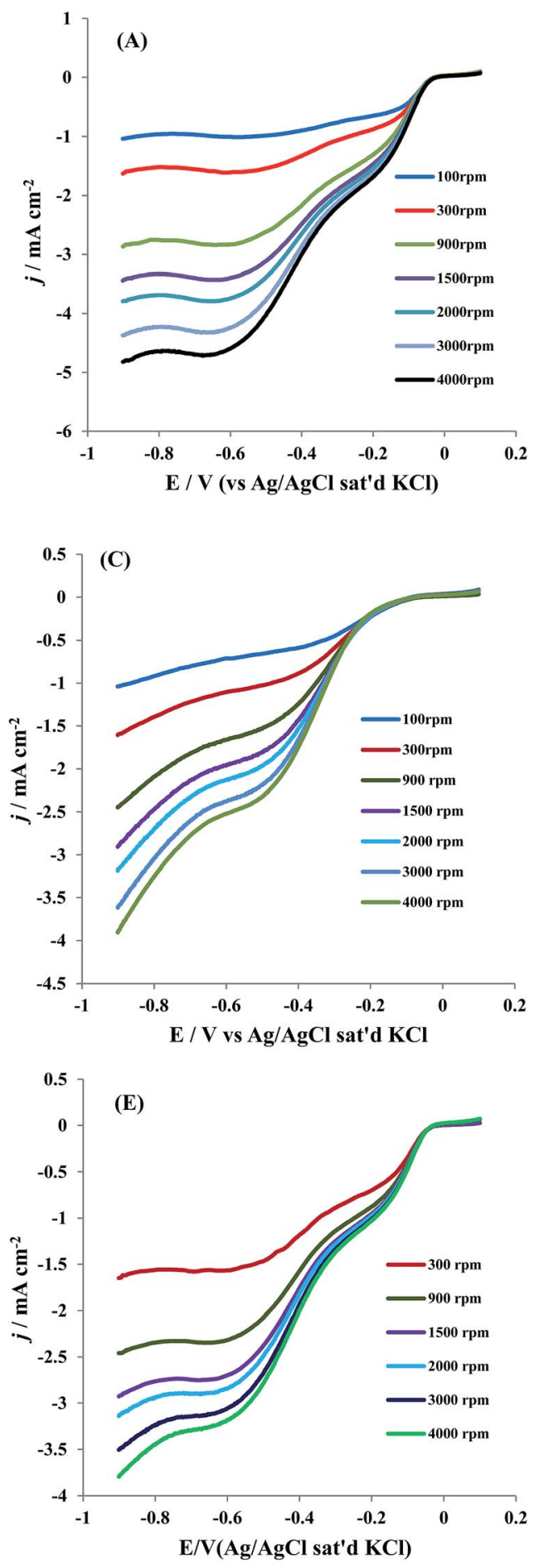

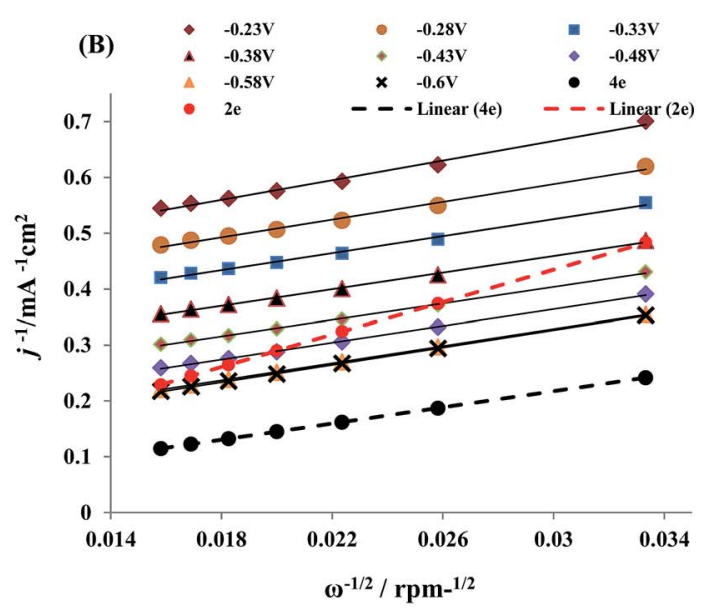

(D)

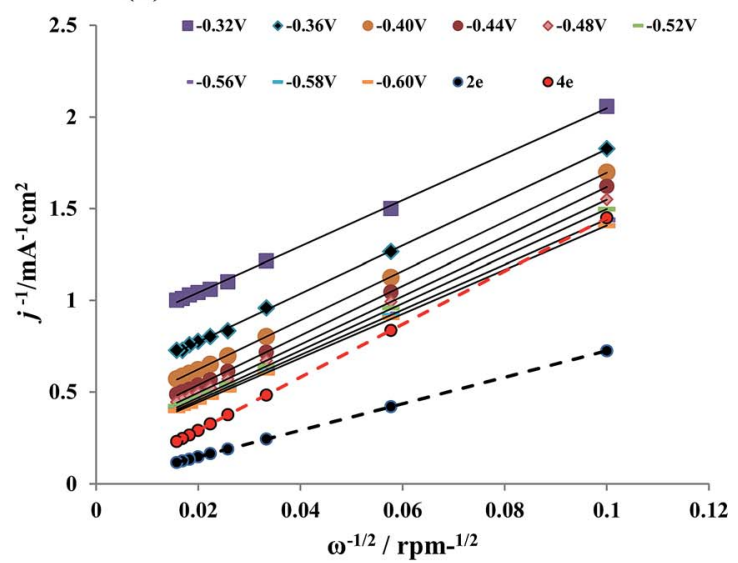

(F)

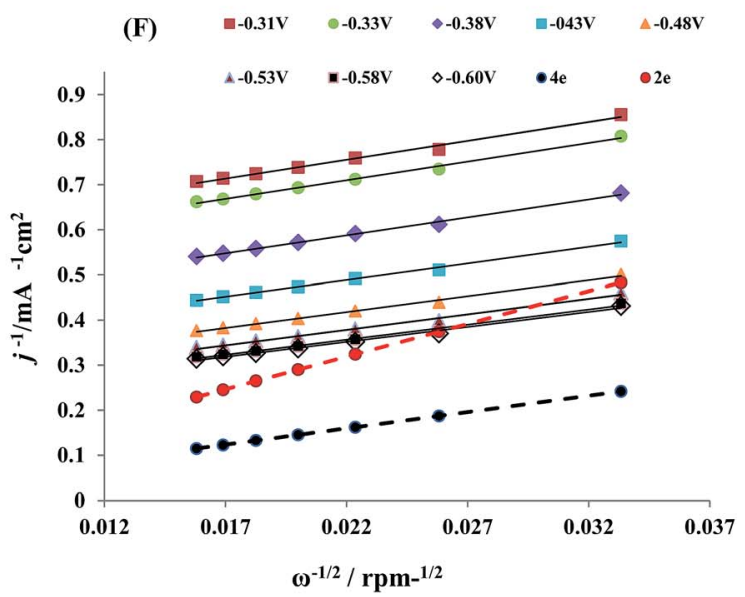

Fig. 6 RDE plots of nanoFeTSPC-O-MWCNT (A), nanoFeTSPC-s-MWCNT (C) and Pt/XC-72 (E) and their corresponding Koutecky-Levich plots (B), (D) and (F) respectively. All data obtained in oxygen-saturated $0.1 \mathrm{M} \mathrm{KOH}$ solution at different rotation speeds (LSV at $10 \mathrm{mV} \mathrm{s} \mathrm{s}^{-1}$.

charged CTAB surface via co-ordinate covalency. The CTABtreated catalysts have been known to exert positive influence on ORR; higher oxygen reduction reaction activity, electrochemical active surface area, and long-term durability compared to commercial catalysts. ${ }^{52,53}$ CTAB is an amphiphilic molecule with a quaternary cationic ammonium head group and a long alkyl chain as tail. The hydrophobic interaction of the alkyl chains of
CTAB molecules on the FeTSPc peripheral positions could prevent the restacking and aggregation of the FeTSPc. Indeed, the CTAB-treatment plays some important roles at improving the performance of the FeTSPc:CTAB functionalizes the FeTSPc, thus minimizing aggregation between the neighbouring FeTSPc molecules. Also, the UV-vis spectra suggest that the CTABtreatment preserves intrinsic electronic properties of FeTSPc. 
Table 2 Comparison of the kinetic parameters for the ORR activities obtained in this work and literature. The number of transferred electrons ( $n$ ) reported was calculated from $\mathrm{RDE}$ in accordance with eqn (1) at $-0.32 \mathrm{~V}$. Each experiment was performed five times with the mean and standard deviation reported in the table ${ }^{a}$

\begin{tabular}{|c|c|c|c|c|c|}
\hline Catalysts & Catalyst loading & $n$ & $10^{2} \mathrm{k} / \mathrm{cm} \mathrm{s}^{-1}$ & $b / \mathrm{mV} \mathrm{dec}{ }^{-1}$ & Ref. \\
\hline nanoFeTSPc-o-MWCNT & $9 \%$ & $3.7 \pm 0.2$ & $1.57 \pm 0.04$ & $216 \pm 10$ & This work \\
\hline nanoFeTSPc-s-MWCNT & $9 \%$ & $2.1 \pm 0.1$ & $1.38 \pm 0.05$ & $371 \pm 16$ & This work \\
\hline $\mathrm{Pt} / \mathrm{XC}-72$ & $80 \%$ & $3.9 \pm 0.1$ & $1.48 \pm 0.05$ & $153 \pm 7$ & This work \\
\hline FePc/SWCNT & $20 \%$ & 3.9 & - & - & 6 \\
\hline PtFeOCPc-MWCNT & $50 \%$ & 3.9 & 2.78 & 180 & 7 \\
\hline $\mathrm{FePc}(\mathrm{CP})_{4} / \mathrm{Gr}$ & $75 \%$ & 3.8 & - & 387 & 10 \\
\hline $\mathrm{g}$-FePc & $50 \%$ & $\sim 4.0$ & - & - & 9 \\
\hline FeOBSPc-MWCNT $^{b}$ & $50 \%$ & $\sim 4.0$ & $37.17 \pm 1.46$ & 124 & 38 \\
\hline
\end{tabular}

${ }^{a}$ PtFeOcPc:iron(II) tetrakis(diaquaplatinum)octacarboxyphthalocyanine, FePc(CP) ${ }_{4} / \mathrm{Gr}$ :iron(III) tetracumylphenoxyphthalocyanine/graphene, gFePc:iron phthalocyanine (FePc) supported on chemically reduced graphene. ${ }^{b}$ FeOBSPc:octabutylsulphonylphthalocyanine complexes of iron. The rate constant was obtained from the electrochemical impedance data.

It may be necessary to emphasize here that the nanoFeTSPc reported in this work is physico-chemically quite different from the iron(II) octabutylsulphonylphthalocyanine complex (FeOBSPc) studied by Mamuru et al. ${ }^{38}$ for ORR. For example, although both are hydrophobic in nature, the FeOBSPc contains eight " $-\mathrm{SO}_{2}-\mathrm{C}_{4} \mathrm{H}_{9}$ " group at the peripheral positions of the FePc, while the nanoFeTSPc only contains four new functional groups " $\left[-\mathrm{SO}_{3}{ }^{-} \mathrm{N}^{+}\left(\mathrm{CH}_{3}\right)_{3}-\mathrm{C}_{16} \mathrm{H}_{33}\right]$ " at the peripheral positions. The nanoFeTSPc is an easy-to-make compound compared to the more synthetically-challenging FeOBSPc complex. In the previous study, the FeOBSPc was studied using the highperforming edge-plane pyrolytic graphite compared to the relatively poor-performing glassy carbon substrate used in the present study. Importantly, the loading of the FeOBSPc on $o$-MWCNT was quite high $(50 \%)$ compared to the mere $9 \%$ loading of the nanoFeTSPc on $o$-MWCNT.

\section{Methanol tolerance}

One of the serious problems in methanol fuel cells is the methanol cross-over effect that leads to high overvoltage, impacting negatively on the ORR activities. ${ }^{54-56}$ The methanol cross-over effect on nanoFeTSPc- $o$-MWCNT and Pt/XC-72 was evaluated in oxygen-saturated $0.1 \mathrm{M} \mathrm{KOH}$ solution with sequential additions of $0.1 \mathrm{~mL}$ of $1 \mathrm{M}$ methanol (Fig. 7).

Fig. 7A shows the cyclic voltammetric (CV) evolutions for the ORR at nanoFeTSPc-o-MWCNT modified electrode in the absence and presence of methanol. There was no noticeable change in the CVs obtained either in the presence or absence of methanol in the oxygen-saturated $\mathrm{KOH}$ solution, clearly proving that the nanoFeTSPc-o-MWCNT catalyst has a very high selectivity for ORR even upon contamination with methanol. However, the performances of Pt/XC-72 modified electrode (Fig. 7B) under the same experimental conditions as for the nanoFeTSPc-o-MWCNT modified electrode (Fig. 7A) showed the opposite behaviour. Upon contamination of the oxygensaturated $0.1 \mathrm{M} \mathrm{KOH}$ solution with methanol, there is an increased oxidation activity of methanol (oxidation peak at $c a$. $-0.24 \mathrm{~V}$ ) by the Pt/XC-72 with a steady deterioration of the ORR peak at $c a .-0.2 \mathrm{~V}$. The ORR peak is almost non-existent after the addition of $0.4 \mathrm{~mL}$ of the $1 \mathrm{M}$ methanol. The results indicate a very strong methanol cross-over effect on the $\mathrm{Pt} / \mathrm{XC}-72$ catalyst
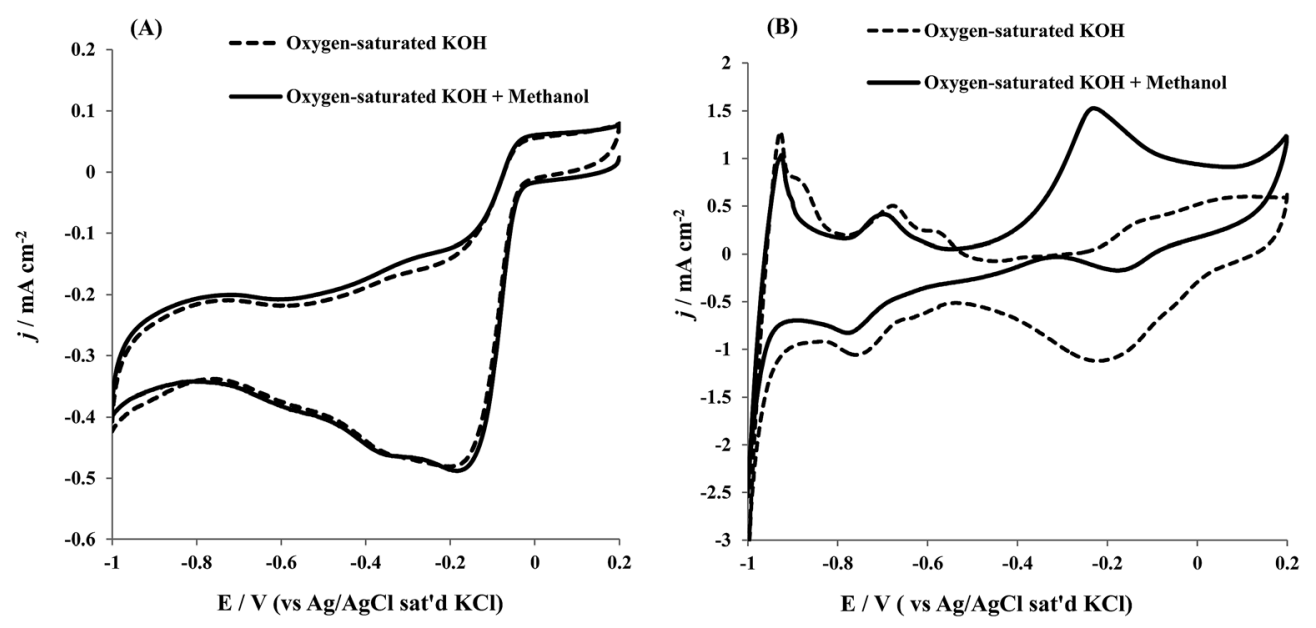

Fig. 7 Cyclic voltammetric evolutions of nanoFeTSPC-O-MWCNT (A) and Pt/XC-72 (B) in oxygen-saturated 0.1 M KOH without (broken lines) and with (straight lines) methanol, scan rate $=25 \mathrm{mV} \mathrm{s}^{-1}$. 
during ORR. Our results compare with other Pt-free ORR catalysts that have been reported to give better performance than $\mathrm{Pt} /$ $\mathrm{C}$ in alkaline electrolytes. ${ }^{56-59}$ For example, Li et al. ${ }^{56}$ reported a strong tolerance to methanol with cobalt oxide based nitrogendoped graphene/carbon nanotube $\left(\mathrm{NG} / \mathrm{CNT} / \mathrm{Co}_{3} \mathrm{O}_{4}\right)$ paper catalyst. Sevilla et $a .^{58}$ proved that, unlike $\mathrm{Pt} / \mathrm{C}$, polypyrrolederived mesoporous nitrogen-doped carbons showed no sensitivity towards the presence of methanol during ORR. Li et al. ${ }^{59}$ showed that, unlike $\mathrm{Pt} / \mathrm{C}$, metal-free phosphorus-doped graphene nanosheets exhibits high immunity to methanol, and thus has much higher fuel selectivity towards the ORR than the $\mathrm{Pt} / \mathrm{C}$ catalysts. Indeed, the strong methanol tolerance shown by our nanoFeTSPc-based catalyst compared to the commercial $\mathrm{Pt} / \mathrm{C}$ is quite promising as it indicates it can potentially be used to design and fabricate highly durable alkaline direct methanol fuel cells for practical applications such as in portable electronics.

\section{Conclusion}

This work describes the use of nanostructured, organo-soluble iron(II) tetrasulfophthalocyanine (nanoFeTSPc) catalysts supported on MWCNTs for ORR. The nanoFeTSPc supported on carboxylated MWCNTs (nanoFeTSPc- $o$-MWCNT) exhibited the best performance towards ORR in terms of high catalytic current density, more positive onset potential, half-wave potential and peak potential, and high catalytic rate constant $\left(k \sim 1.6 \times 10^{-2} \mathrm{~cm} \mathrm{~s}^{-1}\right)$ compared to the catalyst on sulfonated MWCNT (nanoFeTSPc-s-MWCNT) counterpart or the Pt/XC-72 (80 wt\%, Pt loading). The half-wave potential $\left(E_{1 / 2}\right)$ on nanoFeTSPc- $o$-MWCNT is more positive $(\sim 50 \mathrm{mV})$ than that from the commercial $\mathrm{Pt} / \mathrm{XC}-72$ catalyst. In general, the ORR performance followed this trend: nanoFeTSPc-o-MWCNT $>\mathrm{Pt} / \mathrm{XC}-72>$ nanoFeTSPc-s-MWCNT. The nanoFeTSPc-o-MWCNT gave a 4electron pathway, while the nanoFeTSPc-s-MWCNT followed the 2-electron which we related to the possible competition of the catalyst and the sulfonate groups for adduct formation with surface oxygen molecules. The excellent performance of the nanoFeTSPc- $o$-MWCNT correlates very well with the more homogenous dispersion and higher degree of attachment of the nanoFeTSPc on the surface of the $o$-MWCNT than on the $s$ MWCNTs. The nanoFeTSPc-o-MWCNT exhibited excellent tolerance to methanol contamination compared to the commercial Pt catalyst. The low loading of the nanoFeTSPc catalyst on the MWCNT, coupled with its high selectivity for ORR in the presence of methanol compared to the $\mathrm{Pt} / \mathrm{XC}-72$ catalyst makes it a promising non-noble catalyst for alkaline fuel cells.

\section{Acknowledgements}

This work was funded by the CSIR as well as the South Africa's Department of Science and Technology (DST) and National Research Foundation (NRF) under the "Nanotechnology Flagship Programme" (supercapacitors and fuel cell project, Grant no. 69849). OOF thanks the DST/NRF for doctoral bursary under this project.

\section{Notes and references}

1 A. Morozan, S. Campidelli, A. Filoramo, B. Jousselme and S. Palacin, Carbon, 2011, 49, 4839-4847.

2 C. W. B. Bezerra, L. Zhang, K. Lee, H. Liu, A. L. B. Marques, E. P. Marques, H. Wang and J. Zhang, Electrochim. Acta, 2008, 53, 4937-4951.

3 J. H. Zagal, S. Griveau, J. F. Silva, T. Nyokong and F. Bedioui, Coord. Chem. Rev., 2010, 254, 2755-2791.

4 J. H. Zagal, Coord. Chem. Rev., 1992, 119, 89-136.

5 R. Jasinski, Nature, 1964, 201, 1212-1213.

6 G. Dong, M. Huang and L. Guan, Phys. Chem. Chem. Phys., 2012, 14, 2557-2559.

7 S. A. Mamuru and K. I. Ozoemena, Electrochem. Commun., 2010, 12, 1539-1542.

8 W. Li, A. Yu, D. C. Higgins, B. G. Llanos and Z. Chen, J. Am. Chem. Soc., 2010, 132, 17056-17058.

9 Y. Jiang, Y. Lu, X. Lv, D. Han, Q. Zhang, L. Niu and W. Chen, ACS Catal., 2013, 3, 1263-1271.

10 L. Cui, G. Lv, Z. Dou and X. He, Electrochim. Acta, 2013, 106, 272-278.

11 D. Ji, X. Lu and R. He, Appl. Catal., A, 2000, 203, 329-333.

12 K. Ozoemena and T. Nyokong, J. Chem. Soc., Dalton Trans., 2002, 1806-1811.

13 F. Griveau, S. Gulppi, M. Pavez, J. Zagal and H. Bedioui, Electroanalysis, 2003, 15, 779-785.

14 N. Li, M. Zhu, M. Qu, X. Gao, X. Li, W. Zhang, J. Zhang and J. Ye, J. Electroanal. Chem., 2011, 651, 12-18.

15 K. Ozoemena, N. Kuznetsova and T. Nyokong, J. Mol. Catal. A: Chem., 2001, 176, 29-40.

16 W. H. Flora, H. K. Hall and N. R. Armstrong, J. Phys. Chem. B, 2003, 107, 1142-1150.

17 B. Agboola, K. I. Ozoemena and T. Nyokong, J. Mol. Catal. A: Chem., 2006, 248, 84-92.

18 M. Sanchez, E. Fache, D. Bonnet and B. Meunier, J. Porphyrins Phthalocyanines, 2001, 05, 867-872.

19 F. Majedi, S. Zavareh, M. S. Sharif and F. Golestani-Fard, Int. J. Nanosci., 2010, 09, 175-180.

20 M. P. Siswana, K. I. Ozoemena and T. Nyokong, Electrochim. Acta, 2006, 52, 114-122.

21 C. Y. Du, T. S. Zhao and Z. X. Liang, J. Power Sources, 2008, 176, 9-15.

22 Z.-P. Sun, X.-G. Zhang, R.-L. Liu, Y.-Y. Liang and H.-L. Li, J. Power Sources, 2008, 185, 801-806.

23 B. Gao, C. Yuan, L. Su, S. Chen and X. Zhang, Electrochim. Acta, 2009, 54, 3561-3567.

24 J. H. Weber and D. H. Busch, Inorg. Chem., 1964, 4, 472-475. 25 Z.-P. Sun, X.-G. Zhang, Y.-Y. Liang and H.-L. Li, J. Power Sources, 2009, 191, 366-370.

26 O. O. Fashedemi and K. I. Ozoemena, Sens. Actuators, B, 2011, 160, 7-14.

27 V. Zucolotto, M. Ferreira, R. Cordeiro and C. J. L. Constantino, J. Phys. Chem. B, 2003, 107, 3733-3737. 28 H. Günzler and H.-U. Gremlich, IR spectroscopy: an introduction, Wiley-vch, 2002. 
29 A. B. P. Lever, S. R. Pickens, P. C. Minor, S. Licoccia, B. S. Ramaswamy and K. Magnell, J. Am. Chem. Soc., 1981, 103, 6800-6806.

30 V. Zucolotto, M. Ferreira, M. R. Cordeiro, C. J. L. Constantino, D. T. Balogh, A. R. Zanatta, W. C. Moreira and O. N. Oliveira, J. Phys. Chem. B, 2003, 107, 3733-3737.

31 B. Agboola, K. I. Ozoemena and T. Nyokong, J. Mol. Catal. A: Chem., 2005, 227, 209-216.

32 B. Agboola, K. I. Ozoemena, P. Westbroek and T. Nyokong, Electrochim. Acta, 2007, 52, 2520-2526.

33 I. Kruusenberg, L. Matisen, Q. Shah, a. M. Kannan and K. Tammeveski, Int. J. Hydrogen Energy, 2012, 37, 4406-4412.

34 R. Rizo, E. Herrero and J. M. Feliu, Phys. Chem. Chem. Phys., 2013, 15, 15416-15425.

35 Q. Yue, K. Zhang, X. Chen, L. Wang, J. Zhao, J. Liu and J. Jia, Chem. Commun., 2010, 46, 3369-3371.

36 T. J. Davies and R. G. Compton, J. Electroanal. Chem., 2005, $585,63-82$.

37 S. A. Mamuru and K. I. Ozoemena, Electroanalysis, 2010, 22, 985-994.

38 S. A. Mamuru, K. I. Ozoemena, T. Fukuda, N. Kobayashi and T. Nyokong, Electrochim. Acta, 2010, 55, 6367-6375.

39 C. E. Banks and R. G. Compton, Understanding Voltammetry, 2007.

40 Y. Shao, G. Yin, J. Zhang and Y. Gao, Electrochim. Acta, 2006, 51, 5853-5857.

41 J. J. Gooding, Electrochim. Acta, 2005, 50, 3049-3060.

42 R. R. Moore, C. E. Banks and R. G. Compton, Anal. Chem., 2004, 76, 2677-2682.

43 L. R. Faukner and A. J. Bard, Electrochemical Methods: Fundamentals and Applications, Wiley, New York, 2nd edn, 2001.
44 L. Cui, G. Lv, Z. Dou and X. He, Electrochim. Acta, 2013, 106, 272-278.

45 S. Wang, D. Yu and L. Dai, J. Am. Chem. Soc., 2011, 133, 51825185.

46 L. Demarconnay, C. Coutanceau and J.-M. Léger, Electrochim. Acta, 2004, 49, 4513-4521.

47 V. Bambagioni, C. Bianchini, J. Filippi, A. Lavacchi, W. Oberhauser, A. Marchionni, S. Moneti, F. Vizza, R. Psaro, V. Dal Santo, A. Gallo, S. Recchia and L. Sordelli, J. Power Sources, 2011, 196, 2519-2529.

48 G. I. Cardenas-Jiron, J. Phys. Chem. A, 2002, 106, 3202-3206.

49 R. Baker, D. P. Wilkinson and J. Zhang, Electrochim. Acta, 2008, 53, 6906-6919.

50 R. Baker, D. P. Wilkinson and J. Zhang, Electrochim. Acta, 2009, 54, 3098-3102.

51 İ. Koç, M. Çamur, M. Bulut and a. R. Özkaya, Catal. Lett., 2009, 131, 370-380.

52 K. Kakaei and K. Hasanpour, J. Mater. Chem. A, 2014, 2, 15428-15436.

53 K.-W. Nam, J. Song, K.-H. Oh, M.-J. Choo, H. Park, J.-K. Park and J. W. Choi, Carbon, 2012, 50, 3739-3747.

54 E. Antolini and E. R. Gonzalez, J. Power Sources, 2010, 195, 3431-3450.

55 O. H. Han, J. Anal. Sci. Technol., 2011, 2, A168-A172.

56 S.-S. Li, H.-P. Cong, P. Wang and S.-H. Yu, Nanoscale, 2014, 6, 7534.

57 Z.-J. Lu, S.-J. Bao, Y.-T. Gou, C.-J. Cai, C.-C. Ji, M. W. Xu, J. Song and R. Wang, RSC Adv., 2013, 3, 3990-3995.

58 M. Sevilla, L. Yu, T. P. Fellinger, A. B. Fuertes and M. M. Titirici, RSC Adv., 2013, 3, 9904-9910.

59 R. Li, Z. Wei, X. Gou and W. Xu, RSC Adv., 2013, 3, 99789984. 